\title{
INTRODUKTION
}

Da redaktionen af Tidsskriftet Antropologi for snart mange måneder siden indså, at udgivelsen af tidsskiftets 40 . nummer ville falde sammen med overgangen til det gregorianske år 2000 besluttede vi at udnævne denne tilfældighed til en anledning. En anledning ikke at forveksle med årsag - til at lave nærværende temanummer. Det er ment som en tagen bestik af den antropologiske videnskab anno 2000, og som en spørgen om følgende: Hvorfra er vi antropologer kommet, hvor langt er vi nået og - ikke mindst - hvor skal vi hen? Hvad er vor erkendelsesteoretiske arv, hvilke dele af den vil vi vedgå os, og hvad skal vi anvende den til i fremtiden?

Vi inviterede derfor en række forfattere til at deltage i en slags fagteoretisk statusopgørelse og være med til at identificere konturerne af fremtidens antropologi. Konturer, der så småt er ved at komme til syne, mens støvet fra 1980'ernes og 1990'ernes socialkonstruktivisme og dekonstruktion af kernebegreber lægger sig. Og vi stoler ubeskedent på, at der vil være mange læsere til et sådant temanummer, sultne efter et bud på en ,postpostmoderne" antropologi.

I vores call for abstracts stillede vi, som appetitvækker til forfatterne, en skitseret diagnose af nutidens antropologi. Måske, skrev vi, er antropologiens mellemværende med det levede livs mangfoldigheder grunden til, at antropologer relativt sjældent tager sig tid til overvejelser over de videnskabsteoretiske antagelser, der ligger til grund for beskrivelserne. Eller måske skyldes det uviljen mod at skulle privilegere ét særligt videnskabssyn? Har faget opnået sin popularitet i de seneste årtier på bekostning af sin sammenhængskraft? Vil faget udspalte sig i flere af hinanden uafhængige dele, såsom den overordnede differentiering udtrykt i en stadig mere manifest skelnen mellem akademisk og anvendt antropologi? Vil tendensen til tematisk afgrænsning og nye regionale opdelinger $\mathrm{i}$ faget betyde en yderligere atomisering i relativt autonome dele?

Dernæst opfordrede redaktionen forfatterne til at spørge sig selv, hvad der binder disciplinen sammen, og hvori dens videnskabelighed består. Er antropologi en logisk afgrænselig videnskab, gjort af særlige spørgsmål og en fælles begrebsverden? Også selvom faget ikke længere har eneret på sine regioner eller sin metode, og selvom det holistiske perspektiv, den komparative metode og forpligtetheden på betragtninger over det menneskelige som sådan ikke (længere) er kendetegnende? Kort sagt, er der en grænse for relativisme og (de)konstruktivisme, hvis man vil bedrive antropologisk videnskab? 


\section{Mistet uskyld}

Det ligger i selve statusopgørets natur, at man forsigtigt og ikke absolut forholder sig til status quo; i det mindste når det, der gøres op, er en socialvidenskab i konstant bevægelse, hvis udvikling navnlig i de seneste 15-20 år har været så aldeles gennemgribende, at de faglige konsekvenser endnu er uoverskuelige.

Der lader til i artiklerne at være en slags enighed om, at postmodernismens erkendelser er irreversible, om end uegnede til permanent ophold. Det vil sige, at etnografien siden midtfirserne endegyldigt og for altid har mistet sin ungdoms uskyld. Vi kan aldrig vende tilbage til det essenslignende ,race-minus-biologi“-kulturbegreb, der fremstillede menneskelige samfund som selvberoende, selvgenererende $\emptyset \mathrm{er}$ af kultur, der empirisk kunne udgrænses med stor nøjagtighed. Om denne irreversible erkendelses voldsomme betydning så skyldes, at vi først nu formår at se på empirien med den rette sans for ontologi og epistemologi, eller om det er empirien, der simpelthen, med globalisering og kompleksitet, har ændret sig radikalt, er straks mindre klart.

Der er dog enighed om, at empirien har ændret sig radikalt. Det medfører - blandt andet - nogle etiske overvejelser. Det fordrer en erkendelse af, at „os“ versus ,dem“ dikotomien er mindre relevant, end den var så sent som i 1970'erne. Nu ved „,de“, hvad „vi“" skriver om dem, ja, måske er „,de“ endda selv antropologer. Det klassiske etnografiske objekt er altså ikke alene blevet et subjekt, men tillige en samarbejdspartner eller ligefrem en faglig kollega. Dette fænomen, at objektet er rykket tættere på såvel geografisk som kognitivt, er naturligvis ekstra klart, når empirien og genstandsfeltet er Danmark, som det i stigende grad er tilfældet.

\section{Etnografen kommer aldrig hjem}

På den anden side betyder denne ændring af empirien i forhold til fordums tiders antropologi ingenlunde, at skellet mellem det analyserede og den analyserende ophæves. Af simpelt hensyn til fagets overlevelse som videnskabelig disciplin skal disse to niveauer altid holdes ,klinisk“" adskilt. Antropologerne, eller nogle af dem, er måske nok kommet hjem i geografisk forstand, men ikke i analytisk. Marc Augé (1999) spørger polemisk, om vi, nu hvor objektet har mistet sin umiddelbare eksotisme, som nogle mener, lige så godt kan ,overgive os ved lyden af aftryllelsens sirener“? „Nej“, svarer han selv på denne epistemologisk set dystre prognose, som allerede Max Weber empirisk antydede. „Etnografen kommer aldrig hjem [for] nutidens paradoks er således, at lige så vel som al ensretning kalder differentiering frem, så vil al følt mangel på mening rumme mening og kræve at blive gjort meningsfuld. Det er i dette komplekse spil af efterspørgsel og respons, at antropologen måske kan finde nye objekter at reflektere over" (Augé 1999:xi). Vi kommer aldrig ,hjem“ i den forstand, at den analytisk-antropologiske fremstilling af menneskers idéer om verden aldrig vil være i fuld overensstemmelse med disse menneskers fremstilling af samme. Vi er altid ,ude“ og i analytisk afstand i forhold til vores genstandsfelt, også selvom det ligger på Toftegårds Plads.

Forfatterne lader til, fra hver deres position og materiale, at bekræfte dette forhold, og er altså som sådan meget optimistiske på fagets vegne ved at afvise den tilsyneladende opspaltning i henholdsvis teoretisk/akademisk og anvendt antropologi. Antropologi er 
per definition teoretisk-analytisk og som sådan, lig al god videnskab, også anvendelig for dem, der ellers har sans for det. Antropologer kan med godt analytisk arbejde ikke blot analysere „den virkelige verden“, men tillige udfordre dens beskaffenhed og ændre den. Om dette så sker - om de teoretisk funderede analyser tages til efterretning - vil vise sig $i$ en senere fase.

\section{Strukturering og centrifugering}

Nogle forfattere er inde på den uheldige tendens til subkulturalisering og cultural studiesisering af antropologien, som fagets vældige popularitet $i$ ekstradisciplinære kredse såvel som i lægkredse har lokket nogle antropologer ud i. Dette besvarer delvist redaktionens bekymring for, om tema-antropologien, ,,bindestregs-antropologien“, vil atomisere faget ud i delspecialiseringer, der ikke formår at kommunikere på en fælles faglig klangbund. Her mister vi det store kølige overblik. Vi gentager faktisk fejlen med det essentialistiske kulturbegreb, blot på mindre subkulturel skala, og bærer dermed ved til den omsiggribende ontologiske relativisme (kvinder, rastamen, gamle, bøsser og inughuit $e r$ vitterlig ,noget for sig“), til den style-orienterede individualisering og den centerløse kulturelle centrifugering. Derved negligeres eksistensen af et strukturerende, indrammende og kontekstualiserende samfundsbegreb, der transcenderer individ- og gruppeidentiteter og fastholder delanalysernes retmæssige placering inden for en holistisk videnskabstradition. Denne er vigtig at opretholde for at kunne forholde sig til det menneskelige som sådan og muliggøre komparation. Vi skal ihukomme den gode del af den fagteoretiske arv, heriblandt fra de klassiske sociologer, og operere med et samfundsbegreb i tillæg til et kulturbegreb. En antropologi, der har erklæret såvel marxismen som den lingvistisk inspirerede strukturalisme for passé, skal passe på i sin iver ikke at overdrive individets „aktør"-rolle og derved helt overse eller udelukke de lange seje træk i strukturer og processer. Desuden bør vi huske, at uanset hvor vigtigt det var at dekonstruere kulturbegrebets stoflighed og introducere kompleksitet, skal denne teoretiske erkendelse nødigt blokere for en indsigt i, at empirien, flertallet af menneskene i ,det levede liv“, uanfægtet opfatter deres liv som meningsfulde - globaliserede, fragmenterede og komplekse som de muligvis ,er“ - og tænker på deres livsværdier og livsmåder som relativt sammenhængende (Moore 1999:16). Med andre ord skal der passes godt på barnet, når det epistemologisk-grumsede badevand skiftes.

\section{Endestation eller overgang}

Der var megen ægte indsigt at hente i den dekonstruktive tekstdebat, der gennemstrømmede faget i 1980'erne, men den er ikke i sig selv en epistemologisk endestation. Højst en remise, hvor man en overgang tøver lidt før næste afgang. Tekstdebatten påpegede en mængde uheldige traditioner i repræsentationen af data og følgelige forplumring af såvel etnografens egen forståelse som af fagets videnskabelige resultater. Det var aldeles nødvendigt at få gennemrenset fagets analytiske begreber og at få stillet skarpt på repræsentationens forhold til det erkendte. Imidlertid er dekonstruktivismens centerløse spejlkabinet af repræsentationer, hvor multivokale diskurser - efter de store narrativers erklæ- 
rede død - er fritsvævende om hinanden, ikke noget sundt opholdssted for antropologien i længden. Socialkonstruktivismens mest radikale udgaver, hvor selv den fysiske verden er konstrueret, og hvor intet eksisterer uafhængigt af den menneskelige erfaring, er endda uegnet til selv kortere ophold. At antropologien har en tradition for at analysere folks opfattelser af virkelighed, er ikke ensbetydende med, at der ikke findes nogen ekstra-konventionel virkelighed. Denne del af virkeligheden er blot ikke vores centrale genstandsområde. Der lader til at være en generel konsensus om, at antropologi ikke desto mindre er videnskab. Det er ikke en såkaldt eksakt videnskab, men videnskab ikke desto mindre.

Desuden er der enighed om, at nok er dekonstruktivismens bedste erkendelser irreversible, men vi skal videre end det. Dette er en overgang. Og til det formål er det slet ikke så tosset at vende et blik bagud - foruden fremad, som Janushovedet - og se, ikke glemme, hvad fagets kirkefædre lærte os: Om komparation, holisme, struktur, samfund, kultur og det almenmenneskelige som sådan.

God fornøjelse og tak for interessen for de første 40 numre af tidsskriftet!

- redaktionen

\section{Litteratur}

Augé, Marc

1999 An Anthropology for Contemporaneous Worlds. Stanford: Stanford University Press.

Moore, Henrietta L.

1999 Anthropological Theory at the Turn of the Century. I: Henrietta L. Moore (ed.):

Anthropological Theory Today. Cambridge: Polity Press. 